\section{A REMARKABLE DEFORMITY OF THE TEETH AMONG THE INHABITANTS OF THE ADMIRALTY ISLES 1}

THE Russian traveller, M. Miklucho-Maclay, in the course of recent travel in Melanesia, has noticed among the natives of the Admiralty and Hermit Isles a remariable peculiarity in the teeth, the upper incisors

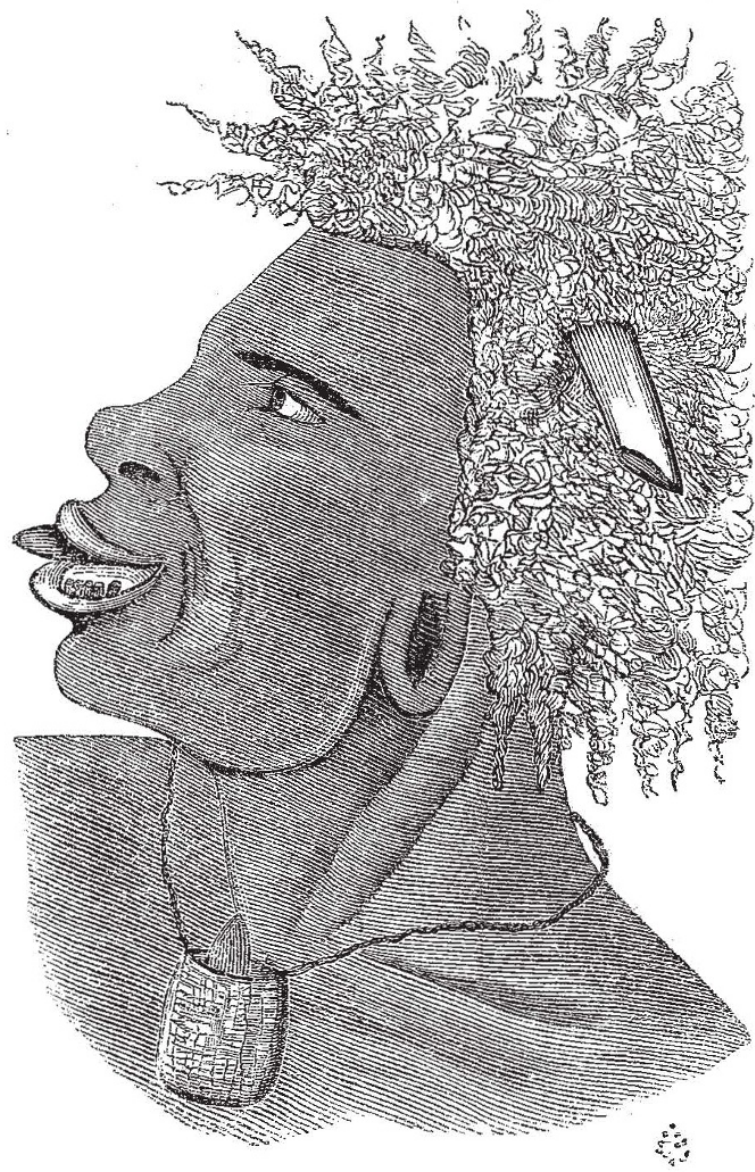

projecting "shovel like," almost horizontally, and to such a degree as to extend even beyond the lips when the mouth is closed. The breadth, moreover, of one of these

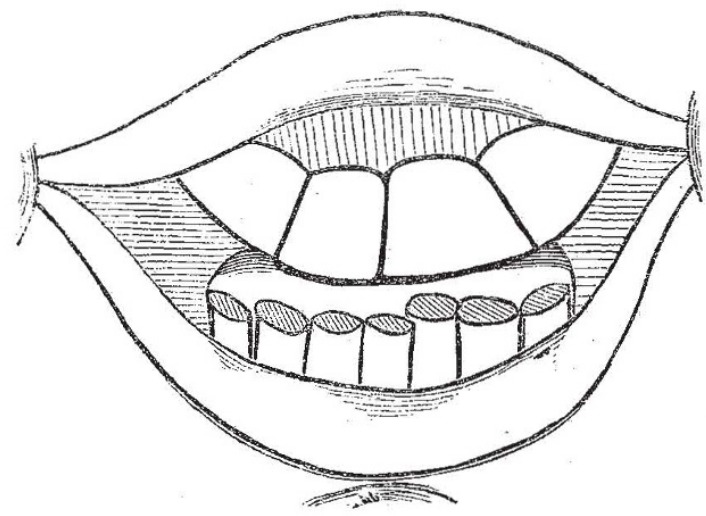

tee'h is at times so great as to equal its visible length; being in the specimen figured as much as 19 millimetres

${ }^{x}$ See a note contributed to the Illustrirte Zeitung of Leipzig by M. Miklucho-Maclay. to $16 \mathrm{~mm}$. of length, measured, of course, from the edge of the jaws, not from the extremity of its fang. As all the teeth have a blackish polish, due to the prevailing habit of betel-chewing, the mouth presents a somewhat ghastly appearance. M. Miklucho-Maclay has nowhere else met with a similar deformity of the teeth, but heard of such, when on the peninsula of Malacca, the race in which it occurs being called "orang-gargassi." " J. C. G.

\section{RAINFALL AND SUN-SPOTS}

WE have received the following communications having reference to Gell. Strachey's paper on the above subject, which we printed some little time back.

The conclusions of Mr. Meldrum as to a relation between the amount of rainfall and the frequency of sun-spots have become a subject of much interest with reference to the possibility of being prepared $10 \mathrm{r}$ such a deficiency of rain in India as may result in a failure of crops and consequent famine. That the varying yearly rainfall at Madras showed on the whole ar rather marked agreement with the sun-spot period, has been known to me for some time, and Dr. Hunter has lately made an examination of the amounts relatively to an eleven-yearly cycle which has excited marked attention on account of its possible practical application. Ger̃. Strachey has made a discussion of the Madras observations in a paper read before the Royal Society, a full abstract of which has appeared in NATURE (vol. xvi., p. I7I). He has sought to show that there is no evidence in the Madras observations of periodicity at all; and that if the rainfalls for each of the sixty-four years were written on slips of paper and drawn from a bag, so that the first amount drawn should be placed to the first year (1813), the second to the next year ( 1814 ), and so on, as well-marked a result would be obtained as is shown by the quantities observed in their respective years. This conclusion he founds on the following method, which he terms a "true criterion of periodicity."

If the differences of the rainfall for each year from the mean of the whole sixty-four years be taken, and the mean of all these differences (without respect to sign) be called the general mean difference; if we arrange the yearly rainfalls in horizontal series of eleven successive years (there will be six such series nearly), and the means for the first, second..... years of the series be taken, these quantities (periodic means) will show the mean variation in the period of eleven years, if any such exist. If now the differences of the yearly rainfalls from the periodic means for the corresponding years be obtained, the means of these, irrespective of sign, may be called the periodic mean differences. In the case of the Madras rainfalls Gen. Strachey finds-

$$
\begin{aligned}
& \text { The general mean difference }=12.4 \text { inches, } \\
& \text { The periodic " } "=11 \cdot 2,
\end{aligned}
$$

and his true criterion of periodicity, though not so definitely stated as might be wished when so important a rule is proposed, appears to be that if there be no periodicity the variation in the periodic means will tend to disappear in a sufficiently long series of observations and the general and periodic mean differences be identical. It seems to me that the disappearance of a variation in the periodic means is here the true criterion of no-periodicity; but though a very large variation exists in the case of the Madras observations, yet Gen. Strachey concludes that since the periodic and general mean differences agree so nearly, there is no tendency to periodicity shown in the Madras observations.

As an illustration of the true criterion, Gen. Strachey

I Man-devil. Orang is the usual Malay word for man, while gargrassi is I Man-divil. Orang is the usual Malay word for man, while
equivalent to the German Qunlgeist, tormenting spirit.-J. C. G. 
takes the two hourly observations of the barometer for tive successive days at Madras, and shows that-

The general mean difference $=0.030$ inches,

The periodic ", " = 0.014 "

Here, he says, a true period existing, the periodic mean difference becomes much less than the general mean difference.

I shall now venture to show that this is no criterion of periodicity. If we represent variations of any quantity for a given time by a curved line, and if we have several such lines of exactly the same form placed one over the other, a straight line passing through the curves, with as much space between the straight and curved lines above as below, will represent the general mean. In a simple curve of two branches the general mean difference will be nearly one-fourth of the amplitude of the oscillation; while, as all the oscillations agree with each other, and therefore with the mean oscillation, the periodic mean difference will be zero. If, however, we displace the individual curves so that as many shall be above as below their mean, both the general and the periodic mean differences will increase, and the difference between these quantities will diminish, till the individual curves are so separated from the mean that none of them is cut by it, when the two mean differences will be equal: Letween this case and that of general coincidence the two mean differences will have values which will differ more or less from each other, according as the individual curves are nearer to, or more remote from, the mean; and the ratio of the one mean difference to the other will tend to a constant value as the number of cycles increases, a ratio which will depend for its value on the mode of distribution of the incividual curves and of the irregular deviations from the mean.

Gen. Strachey's illustration is from a case approaching coincidence; hundreds of cases, however, may be found of the other class, especially when, as in this instance, only a few periods are in question. Thus, taking two hourly observations of the barometer at Simla during six days in the beginning of January, I 345 , I find-

The genteral mean difference $=0.0634$ inches,

The periodic ", $=0.0615$,

and if the last day of the six be omitted so as to have an odd number of days, I find-.

The general mean difference $=0.0656$ inches.

The periodic " " = 0.0634 ,

Gen. Strachey's conclusion from the Madras rainfall observations is in fact that because the periodic mean difference was only one-tenth less than the general mean difference, there was no evidence of periodicity whatever; here we have a large and regular semi-diurnal period (the whole mean range being $0^{\circ} \mathrm{c} 70 \mathrm{inch}$ ) where the periodic is not one-thirtieth less than the general mean difference.

I may add that when the true sun-spot period of ten and a half years is employed for the Madras rainfall observations, I find-

The general mean difference $=12^{\circ} 4$ inches,

The periodic $", \quad=10 \cdot 2$,

quantities which differ by five times as much as those found for the true periodic variation of the barometer at Simla.

I have taken the variation chosen by Gen. Strachey to illustrate this question, but the fact that the difference of the general and periodic mean difference is no criterion of periodicity might have been shown equally well with cases more resembling that of the rainfall, where the irregular variations are large compared with those following a known period; I cannot here, however, enter into details and notice only the objections offered by me to Gen. Strachey's paper when it was read before the Royal Society.

It would be easy to show that the Madras rainfall observations, taken alone, give results which are remarkab'e in several respects. Thus, Ist, They show a mean oscillation larger for about ten (nine to eleven) years than for any other duration. 2nd. When the mean variations for a period of ten and a-half years are represented by a function of sines they give the yearly mean rainfall $(y)$ in the period, $y=62 \sin \left(\theta+310^{\circ}\right)$, showing the large range of $12 \%$ inches. 3 rd. This representative equation gives the epochs of maximum rainfall in the years of maximum sun-spots, or as nearly so as would be given by the mean sun-spot areas represented by a similar expression. ${ }^{1}$

On the other hand, the irregularity in the amount of rainfall from year to year is so great that the probable error of the periodic means is too considerable to give any great weight to this result alone. ${ }^{2}$ When observations during a sufficiently large number of cycles have been obtained, so as to make the probable error of the means small compared with the range of the pericdic variation, then there will be a general acceptation of Gen. Strachey's remark: "It is hardly conceivable that there should be a coincidence with the sun-spot period, such as is supposed to be found at Madras, based on any physical cause which should not in some way be discernible in the rainfall at Bombay and Calcutta" (NATURE, vol. xvi. p. I72), He has then taken five cycles of eleven years' rainfall at Bombay, and four cycles at Calcutta, and testing them by his criterion he obtains results quite similar to that for Madras.

I have only the periodic means for the five eleven-yearly cycles at Bombay now before me, but seeking from these the representative equation of sines as for Madras, and repeating the latter for comparison, I find-

$$
\begin{array}{llll}
\text { Bombay } \quad \ldots & \ldots & y=6.1 \sin \left(\theta+316^{\circ}\right) \\
\text { Madras } & \ldots & \ldots & y=6.2 \sin \left(\theta+310^{\circ}\right)
\end{array}
$$

Both equations give almost exactly the same range of the oscillation and nearly the same epochs of maximum and. minimum as the sun-spots. ${ }^{3}$ This result, which was wholly unexpected by me, is all the more remarkable that the two places are on the opposite coasts of India, and have their rains from different quarters. Calcutta, with a sufficiently large number of cycles, might also have agreed with Bombay and Madras, which is not the case, however, with four cycles only. In each case the criterion would show that no periodicity exists.

I. cannot, then, agree with Gen. Strachey as to his test of periodicity nor to the conclusions he has deduced from it. I will not enter here into the consideration of the weights which may be given to results founded on the known principles of the calculus of probabilities, nor into the question whether the rainfall, not at one or two stations only, but over a country or the whole globe, may not show some relation to the sun-spot period as Mr. Meldrum believes, and as I think quite possible, judging from other results of solar actions. This relation, however, it appears to me has still to be proved, though the observations considered by Gen. Strachey are, on the whole, so much in its favour as to encourage further investigation.

Lyndhurst, New Forest, July I 8

JOHN ALLAN BROUN

In the paper read by Gen. Strachey before the Royal Society, May 24 (see NATURE, vol, xvi. p. 171), "On the alleged Correspondence of the Rainfall at Madras with the Sun-spot Period, and on the True Criterion of Periodicity in a Series of Variable Quantities," certain conclusions are arrived at which render it desirable to test the value of the criterion of periodicity employed. This is the more necessary when it is considered not merely that the principle, if a sound one, must be of T The years given by the equation, the series commencing with $\times 8{ }_{3}{ }^{\circ}{ }^{\circ}$, are $1817.8,1828^{\circ} 8,183^{8} \cdot 8,1849^{\circ} 8,1859^{\circ} 8,7870^{\circ} 8$. ' 1 'he condition that an oscillation should agree in its epochs of maximum and minimum with those of a known phenomenon (a very weighty ore when the chances are to be $\mathrm{CO}_{2}$ sidered) has been neglected by weo. Strachey altrgether.

${ }^{2}$ Tbis refers to the periodic means deduced from the observed quantities the above equation for Madras gives the observed means with a probable error of le s than 3 inches. 3 The first cycle at Bombay begins with the same year, $\left(1824_{4} \cdot 5\right)$ as the
second cycle for Madras. 
extensive application in physical research, but also, and more immediately that the conclusion arrived at seriously affects the great modern problem of Indian administration, viz, the food-supply of the people. The conclusion is that in the case of the rainfall observations of Madras, which have been discussed by Dr. Hunter, the Director-General of Statistics to the Government of India, the evidence is not sufficient to $\in$ stablish either any periodicity or a correspondence such is Dr. Hunter points out. The correctness or incorrectness of Gen. Strachey's views will, it is evident, materially influence the line of action taken by the Government in dealing with the disastrous famines consequent on the recurring droughts of Southern India.

The criterion of periodicity brought forward by Gen. Strachey will appear from what follows. The mean rainfall at Madras for the sixty-four years is $48.5 \mathrm{I}$ inches; if we take the difference between this mean and the rainfall of each individual year, and average the results, we obtain $12 \% 40$ inches as the arithmetical mean of the sixtyfour differences. If we now partition the sixty-four years' rainfall into six sun-spot cycles of eleven years each, and take the difference between each individual year's rainfall and the mean of that term of the sun-spot cycle in which that year's rainfall stands, and then average these sixtyfour new differences, we obtain II.2O inches as the arithmetical mean. Since 1240 inches, the mean difference of the individual observations from the mean of the whole series, is, by the latter process, only reduced to II'20 inches, or about Io per cent., Gen. Strachey concludes that the supposed law of variation obtained from the means of the six eleven-year cycles hardly gives a closer approximation to the actual observations than is got by taking the simple arithmetical mean as the most probable value for any year ; and that the evidence, therefore, is not sufficient to establish any periodicity in the rainfall of Madras, or any correspondence between it and sun-spots.

In illustration of his meaning Gen. Strachey applies his criterion of periodicity to the diurnal barometric oscillations at Madras, in which a well-ascertained periodicity exists. The result of the calculation is that the mean difference of all the individual observations from the mean of the whole series is 30 , whereas tine mean of the differences between the two-hourly individual observations and the averages of the same hours is reduced to 7 , thus indicating, it is added, the clistinct presence of a periodicity.

In concluding against the presence of any periodicity in the rainfall of Madras, Gen. Strachey makes these two assumptions:-(I) If there be a periodicity in the rainfall of this part of India, it would be made apparent by applying his criterion of periodicity to the observations; and (2) the difference between the two arithmetical means calculated as abovc must exceed at least to per cent.

The diumal barometric oscillation at Madras is so regular a plenomenon that it was scarcely worth while to make the calculations, since one could have made a close approximation to the averages 30 and 7 by a simple inspection of the figures. Further, this periodicity which has been selected is altogether inappropriate to the subject in hand, as no one could possibly imagine for a moment that any periodicity which might characterise the rainfall of Madras would exhibit an approach to such regularity of occurrence as characterises the curve of the diurnal oscillation of the barometer at that place. The periodicities which suit the subject before us are such as are presented by the curves of the diurnal barometric oscillation in the British Isiands.

Let us then apply Gen. Strachey's true criterion of periodicity in the examination of such a curve, taking for our $\epsilon \mathbf{X}$ imple the barometric observations at Valencia for the month of December, 1876 , as published in the Hourly Readings at their seven observatories, by the Meteorological Committee for that month. The examination will at the same time test the value of this new criterion as an implement of scientific research.

The mean of the whole 744 observations is 29256 inches. The differences of the individual 744 observations from $29^{\circ} 256$ inches give an arithmetical mean differerice of 0.3372 inch: and the differences betwees each of the individual 744 observations and the means of their respective hours give an arithmetical mean difference of 0.3369 inch. Looking at the individual hours the largest differences are 0 ' 3434 inch and $0^{\circ} 3413$ inch at ro P.M., and $0^{\circ} 3444$ inch and $0^{\prime} 3459$ inch at 6 A.M. Thus the difference of these two arithmetic means is only 0.0003 inch, and the largest difference for any hour amounts only to $0^{\circ} 002 \mathrm{I}$ inch.

Now Gen. Strachey concluded against the presence of a periodicity in the rainfall of Madras on the ground that the two arithmetical means differed oniy ro per cent. from each other. It follows $a$ fortion, if this new criterion is of any value, that the presence of a periodicity in the diurnal barometric oscillation at Valencia during December last be concluded against, inasmuch as the difference between the two arithmetical means is only $\frac{1}{30}$ per cent. and not rising quite to I per cent, for any of the twenty-four hours.

The averages for the month, however, show in an unmistakable manner the presence of such a periodicity. The mean pressure there fell to $29^{\circ} 24.5$ inches the morning minimum at 7 A.M., rose to $29^{\circ} 263$ inches the morning maximum at II A.M., fell to $29^{\circ} 23^{8}$ inches the afternoon minimum at 3 P.M., and rose to $29^{\circ} 273$ inches the after. noon maximum at lo P.M., the time of occurrence of these phases of the curve differing no more than an hour from the mean periods for Valencia at this season of the year. The periodicity is, as stated, a well-marked one, the sum of the diumal oscillations amounting to $0.106 \mathrm{inch}$ being three-fiftbs of the sum of these oscillations for Madras which average for December 0.174 inch. We do not require to remind our readers that the phenomena of the diurnal oscillations of the barometer take their place among the most universally accepted and best established periodicities of science.

In the concluding paragraph of his paper Gen. Strachey apparently applies another criterion to the Madras rainfall, which consists in the comparison of the successive combination of the observations, beginning with one eleven-year cycle, and then combining two cycles, and so on, till the whole six cycles were united. The result arrived at by this treatment of the figures, is that the successive means of the differences between the mean rainfall for the combined cycles and the mean for the several years of the cycle when combined, show no appreciable periodicity.

With reference to this mode of testing the question, it may be enough to say that even were the result of sach an examination as adverse as possible, it conld not be used as a conclusive argument against the existence of periodicity, for the very plain reason that we are investigating a periodicity for which only six terms or separate cycles are available, and in these eycles the non-periodical elements bulk largely. But the following table, referring to the portion of the diurnal barometric curve between the morning and evening minima at Valencia for December last will illustrate the point :-

\begin{tabular}{|c|c|c|c|c|c|c|c|c|c|c|}
\hline & \multicolumn{5}{|c|}{$\Lambda, M$} & & \multicolumn{3}{|c|}{ T.M. } \\
\hline & & 7 & 8 & 9 & xo & II & noon & I & 2 & 3 \\
\hline \multicolumn{2}{|l|}{ Menns for month } & $\begin{array}{l}\text { inches. } \\
29^{\prime} 245\end{array}$ & $\begin{array}{l}\text { is. } \\
247\end{array}$ & $\begin{array}{l}\text { in. } \\
252\end{array}$ & $\begin{array}{l}\text { in. } \\
=559\end{array}$ & $\begin{array}{l}\text { ir.. } \\
2 \delta_{j}\end{array}$ & in. & $\begin{array}{l}\text { in. } \\
346\end{array}$ & $\begin{array}{l}\text { in. } \\
\text { 24t } \mathrm{I}\end{array}$ & $\begin{array}{l}\text { in. } \\
{ }_{23} 8\end{array}$ \\
\hline \multirow{5}{*}{ Days of month } & $3 \cdots$ & $28^{\circ} 511$ & 533 & 550 & $5^{5 I}$ & 562 & 555 & 546 & 535 & 516 \\
\hline & $3-4 \cdots$ & 28.490 & .507 & .527 & .541 & $55 x$ & 552 & 554 & 556 & 550 \\
\hline & $\begin{array}{l}3-5 \ldots \\
3-6 \ldots\end{array}$ & $\begin{array}{l}28498 \\
28.589\end{array}$ & 502 & $\begin{array}{l}5 \mathrm{I}_{4} \\
6 \mathrm{r}_{3}\end{array}$ & $\begin{array}{l}.526 \\
.627\end{array}$ & $\begin{array}{l}534 \\
637 \\
637\end{array}$ & $\begin{array}{r}535 \\
640\end{array}$ & $\begin{array}{l}537 \\
644\end{array}$ & $\begin{array}{l}54 \mathrm{E} \\
6447\end{array}$ & $\begin{array}{l}544 \\
652\end{array}$ \\
\hline & & $28^{\circ} 04$ & 707 & 723 & $73^{8}$ & $74 S$ & $75 x$ & $75^{6}$ & 760 & 767 \\
\hline & & & .880 & 899 & 918 & '931 & 935 & $94^{2}$ & 947 & 957 \\
\hline
\end{tabular}


The observations of the third will be seen to follow, though somewhat roughly, this portion of the curve for the month. The means of the third and fourth show a greater divergence from the monthly curve, and so on through the combinations, each successive combination showing instead of a continted approximation to, a continually increasing divergence from, the mean hourly variation of the month. It is this consideration, to which Gen. Strachey does not appear to have given due weight in his paper, which has led Meldrum and others in their investigation of periodicities of the rainiall and temperature, to extend their inquiries not only over lengthened intervals of time, but also over as wide areas as possible.

It may be added, that this new criterion of a periodicity enunciated and applied by Gen. Strachey at a meeting of the Royal Society in May last would, were it accepted, equally sweep from our view scores of periodicities now everywhere accepted, and effectually foreclose inquiry in many fields of research in which science is certain to reap brilliant results, namely, in those departments of research in which the non-periodical are very largely in excess of the periodical variations, of which meteorology may be regarded as presenting the most numerous and best illustrations.

\section{GEOLOGICAL NOTES}

German Geological Surveys-- (I) Austria.--The programme of the Austrian Geological Survey for this year shows that the work is advancing, as it has been doing for some time past, mainly in two directions, one lying on the extreme cast, the other on the far west of the empire. In the Tyrol two sections or parties are in the field; one of these, under Dr. Stache, and Mr. F. Teller, is investigating the crystalline masses of the Central Alps along both sides of the Vintschgau; the other, under Dr. E. v. Kiojsisovics and Messrs. M. Vacek and A. Bittner, is engaged among the sedimentary formations between Botsen and the Venetian frontier. On the other side of the empire, in Eastern Galicia, Bergrath C. M. Paul and Messrs. Tistze and Lenz are busy among the Carpathians and their spurs to the south of Stanislawow. The vice-director of the Survey, Bergrath D. Stur, will also this year publish his researches on the flora of the Carboniferous period. The whole of the operations of the Survey are controlled and directed by the able hands of Ritter von Hauer.

(2) Province or Prussia.--Besides the national survey organised and paid by the government for the investigatien of the geological stucture of the kingdom of Prussia, there is in progress wijer the auspices of the PhysicalEconomical Society of Königsbere a geological investigation of the Province of Prussia with the publication of a map on the scale of $\frac{7}{\overline{1} 000 \overline{0}}$. It might seem at a first glance that this wide alluvial plain could hardly offer much opportunity for geological observations or for much varicty of colouring on the map. But by means of careful examination of the surface and well-arranged borings below it, much valuable information is being obtained regarding the structure and history of the alluvial, peaty, and drift deposits of the Baltic plain of Prussia. The lively intesest which has been raised on all sides by the undertaking has suggested the idea to publish yeaxly an account of the progress of the work with notices of the more interesting observations and discoveries, and such additional information from other investigators or from other countries as may throw light upon the geological history of the province. Dr. Alrred Jentsch has prepared the first Fahresbericht, which appears in the Transactions of the Physical-Economical Society. After a brief account of the preparation of the map, and of the various boring operations he gives an interesting résumé of the geology and physical geography of East. Prussia, including the variations of water-level in the Vistula and Pregel, the peat-mosses, marls, alluvial clays, drifts, brown-coal, and amber-deposits, with the cretaceous, Jurassic, ant palæozoic rocks made known by boring explorations,

GEOLOGICAL SURVEY OF NEWFOUNDLAND. $-M r_{0}$ Murray has published a second edition of the Index Geological Map of New foundland on the scale of twentyfive miles to an inch. It is of course brought up to date, and exhibits with great clearness the distribution of the various rocks of the colony. The remarkable serpentines, slates, and metamorphic rocks overlying the sandstones of the Quebec group on the west side of the island, are so inserted as to show distinctly their unconformable relations to the rocks below them. Four sections are likewise placed upon the map for the explanation of the geological structure of different regions, The map, in regard to execution, is all that could be desired, considering its small scale and provisional character. Mr. Murray's Report for 1876 has just been issued. The ice which hugged the coasts so late last year prevented a start being made until the end of June. During the few months available for exploration, Mr. Murray and Mr. Howley succeeded in mapping some portions of the interior about the Gander and Gambo rivers. As usual the routes lay along the rivercourses where almost the only geological observations can be made, the intervening country being covered with swamps or forests. The Report shows that considerable areas of good agricultural land lie in the interior, and that while large masses of valuable timber exist they need to be guarded against the ignorant and wanton operations of lumber-men.

\section{CHEMTCAE NOTES}

NEW CHROMIUM AND MANGANESE COMPOUNDS,Some new compounds of chromium and manganese have lately been prepared and examined by Mr.J. B. Hannay, who has communicated a parer on the subject to the Glasgow philosophical Society, On examining any general list of carbon compounds it is to be remarked that, however complicated their structure, they are not as a rule decomposed by water; on the other hand complex compounds of other elenents are as a rule decomposed by this substance into two or more simpler componods. Mr. Hannay was therefore induced to examine wheher carbon is or is not the only element capable of forming series of bodies of complicated structure; and whether the existence of water on this earth is the reason of our not having complex bodies with other elements then carbon for their basis. The plan adopted was to take some complicated substance (containing no carbon) which. is decomposed by water, find a solvent for it, and act on it with other reagenss out of contact of air and moisture. The substance used was oxychlorid of chromiun, $\left(\mathrm{CrO}_{2} \mathrm{Cl}_{2}\right)$, and the solvents employed, carbon oisulphide and carbon tetrachloride. Mr. Hannay has devised ar apparatus which allows of the substance being precipitated, filtered, washed, dried, and weighed off for analysis without coming in contact with air or moitture. The following is a list of the chromium compennds prepared by him :-

$$
\begin{aligned}
& \mathrm{Cr}_{2} \mathrm{Cl}_{4} \mathrm{SO}_{3} \\
& \mathrm{Cr}_{2} \mathrm{Cl}_{4} \subseteq \mathrm{O}_{2} \\
& \mathrm{Cr}_{2} \mathrm{Cl}_{4} \mathrm{Br}_{2} \text {. } \\
& \mathrm{Cr}_{2} \mathrm{Cl}_{4} \mathrm{~S}_{2} \mathrm{O}_{2} \text {. } \\
& \mathrm{Cr}_{2} \mathrm{Cl}_{6} \mathrm{~S} \text {. } \\
& \mathrm{Cr}_{2} \mathrm{Cl}_{4} \mathrm{Br}_{2} \mathrm{~S} \text {. } \\
& \mathrm{Cr}_{2} \mathrm{Cl}_{4} \mathrm{~S}_{2} \text {. }
\end{aligned}
$$

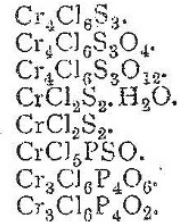

Mr. Hannay has prepared some analogous manganfse compounds, but the analyses of these have not as yet been finished.

COMPLEX INORGANIC ACIDS-Dr. W. Gibbs has lately obtained a series of new inorganic acids formed 